\title{
Vulnerability of Transport Networks to Multi-Scenario Flooding and Optimum Location of Emergency Management Centers
}

\author{
Alfredo Pérez-Morales ${ }^{1,+}+\mathbb{D}$, Francisco Gomariz-Castillo $1,2, *,+(\mathbb{D})$ and Pablo Pardo-Zaragoza ${ }^{1,+}$ \\ 1 Department of Geography, University of Murcia, 30100 Murcia, Spain; alfredop@um.es (A.P.-M.); \\ pardozaragoza@gmail.com (P.P.-Z.) \\ 2 Euro-mediterranean Water Institute (IEA), 30100 Murcia, Spain \\ * Correspondence: fjgomariz@um.es; Tel.: +34-968-899-851 \\ + These authors contributed equally to this work.
}

Received: 24 April 2019; Accepted: 5 June 2019; Published: 8 June 2019

\begin{abstract}
Floods are the climatic factors that cause more significant impacts on transportation infrastructures. This circumstance could get worse, taking into account climate change effects. The literature points out different adaptation measures to minimize the possible increasing effects caused by climate change. Among them is the improvement of the vulnerability of a transport network and Emergency Management Systems. The effective management of emergencies is of vital importance to minimize the potential damage resulting from a catastrophe. Given such circumstances, analysis of the vulnerability of networks is a technique whose results highlight deficiencies and serve as support for future decisions concerning the transformation of the network or the installation of new emergency centers. The main objective of this research is to highlight the vulnerability of the road network in a variety of multi-contingency scenarios related to flooding and to identify the optimal location for a new emergency management center based on that analysis. The results obtained could be used in urban planning tasks to improve the resilience of urban areas in the face of an increase in flood episodes caused by climate change.
\end{abstract}

Keywords: flood risk assessments; vulnerability of networks; emergency management; geographic information systems; open source

\section{Introduction}

The quality of transportation planning and management is critical for the functioning of a city, and issues of urban climate change adaptation and mitigation require attention. The list of impacts is extensive, covering structural and material damages of many different types and associated disruption of transportation services for users depending on the type of transportation facility, its location relative to waterways, and the types of materials and design used [1,2].

According to [3], there are two fundamental options for risk management in the transportation sector. One is by mitigation measures in cities related to greenhouse emissions (transport system as a threat of climate). The second option is reducing risk using adaptation (climate change as a threat to the transportation system). The vulnerability of transportation assets to physical hazards, stemming from the existing spatial and economic organization of the city and its transport system, depends on a range of factors. Among those, the following can be suggested: (1) design and spatial layout of transport infrastructure; (2) basic urban form-high-density settlements with mass transit systems, or mostly motorized transportation with low densities; (3) availability of resources to keep transportation systems functioning in both disaster and non-disaster conditions. However, carrying out this type of 
task in previously occupied spaces is a very difficult task and, therefore, there is no alternative but to concentrate efforts on structural actions to protect the transport network or the improvement of emergency management as a measure of reducing vulnerability and increasing resistance.

Some techniques, such as the analysis of the vulnerability of transport networks [4], have acquired particular attention. According to [5], the vulnerability of a network refers to the capacity to continue operating following a disruption. In other words, the degree of susceptibility of a network to specific incidents that may lead to reduced service or accessibility levels.

In the case of floods, analysis of the vulnerability of the network status is a complex task determined by how the hazard takes place. This type of analysis mainly requires performing specific simulations that show those sections of roads that are most sensitive to being interrupted or even isolated. The number of simulations depends on the combination of floods in different channels crossed by the roads. When the obtained interruption scenarios are treated in a synthesized way, they provide a final map of the network's vulnerability to flooding. This cartography facilitates identification of the most affected sectors, and according to [6], this type of study is among those known as a full scan approach. Some examples can be seen in the literature: For Australia [7] and Hong Kong [8].

Once the most common disruptions are identified, strategies focus on how to solve those connection problems in order to improve accessibility in the face of any event. There are different ways to do this [9]. On the one hand, there are those that increase the network connections, so that the effects of interruption will be less severe during flooding since alternative routes can be taken. Some examples are given in [10-15]. However, such densification or redundancy in the network is not always possible, nor always the most appropriate. Newly built-up areas increase the demands on emergency services, leading to the need for alternative solutions. In light of the above, the possibility arises of relocating existing emergency management centers or of increasing their number in places where the distance from existing centers exacerbates their isolation. In other words, rather than increasing the number of network sections, a commonly called location-allocation analysis of emergency management centers is usually developed in order to reduce the response time in areas where help is needed [16-19]. To identify possible new sites through an objective decision-making process, a map of the vulnerability of a network to flooding is needed.

Various methodologies have been followed in the analysis of vulnerability of the transport network to several natural and human hazards; among them are: complex transport and networks theory [13,20-22], statistical confidence [23] and, perhaps the most widely used, applied GIS graph theory $[5,12,24]$. The present study uses a combination of GIS and graph theory. Based on the principles of graph theory, the network is understood as a set of nodes or vertices interconnected by arcs or sections [25]. Accordingly, this is useful to verify the number of sections and nodes that remain connected to a network after been flooded. It also helps to recognize the elements that are critical for improving safety. As regards location allocation methodologies based on GIS a, there is an extensive literature on this type of methodologies [26-28]. This work has as a substantial novelty, which is the consideration of vulnerability to transport networks as a determining factor for the choice of locations of new centers of emergency management.

The aim of the present study is to propose and evaluate a simple method to analyze the vulnerability of networks in the face of multiple flood scenarios and obtain the optimal location of a new (Proposed) Emergency Management Center (PEC) to minimize those losses of accessibility that can not be resolved by an increase in network density. The proposed method has been evaluated in the urban and suburban setting of Murcia, an area with severe flooding problems.

\section{Description of the GIS Approach to Evaluate Vulnerability and Obtain an Optimum Location of PEC}

The work process proposed in this paper (described in the following subsections) has been implemented using Open Source software. To store and analyze vectorial data, the research used Relational Database Management System (DBMS) PostgreSQL 9.5 with PostGIS 2.3 and PgRouting 
extensions. PostGIS [29] is an extension to PostgreSQL which adds spatial capabilities by adding spatial data types, functions, operators, and indices for spatial data handling. On the other hand, PgRouting adds network analysis functionalities to PostgreSQL / PostGIS databases. Finally, the Quantum GIS (QGIS) program and Python scripting language were used to automate the tasks involved in the processing and management of spatial information.

Lastly, the statistical analysis of the results was performed with R-CRAN [30]. The advantage of R-CRAN is that it includes a large number of advanced analysis functionalities, such as the robust version of one-way ANOVA used in this paper to identify the optimal location.

\subsection{Design Workflow}

Figure 1 presents a conceptual scheme that summarizes the work process. Three work blocks were established. The first block corresponds to an analysis of the vulnerability of the road network according to the accessibility of different points from existing emergency management centers. The block is subdivided into four: (A) data gathering and filtering; (B) preprocessing of the information; (C) costs matrices; (D) Origin-Destination Matrices (ODM) and cartographic results. After establishing the most difficult to reach zones, the second work block (E) is devoted to developing a method to improve the problems related with sites that show vulnerability by selecting a new site for a PEC. The third block defines the process of validation and evaluation of the results, which includes expert evaluation and the decision-making bodies. This section includes the proposal of decisions to be made and the final location of the PEC.

The main concepts described in the conceptual scheme (Figure 1) and in the rest of the subsections are:

- Network: The road network consists of a system of interconnected carriageways which are designed to carry road vehicles.

- Service area: A network service area is a region that encompasses all accessible streets (that is, streets that are reached by an emergency center first).

- $\quad$ PEC: New (Proposed) Emergency Management Center (PEC).

- Cost Matrix: The OD cost matrix finds and measures the least-cost paths along with the network from multiple origins to multiple destinations.

- $\quad$ Flood scenarios: Each of the possible combinations without repetition of the flood zones.

- Network scenarios: Each one of the simulations made in the displacements from the emergency centers to each node of the network, considering the interruptions that may occur due to the flood scenarios.

\subsection{Block I: Obtain Current Centers}

The work process is initialized with the introduction and filtering of the required information: (a) Network layer and (b) flood polygons. As an example, in the present study, the physical aspect -hazard- is characterized using spatial information from the National Cartographic System of Flood-prone Zones (SNCZI in its Spanish initials) [31], the most precise open source on flood-prone areas and water depth with different return periods. It is available in raster form $(0.5 \times 0.5 \mathrm{~m})$ and was drawn up following the principles of Directive 2007/60 [32] on the evaluation and management of flood risks. The raster associated with a return period of 100 years (RP100) was chosen for this study as flood-prone area and water depth; Return period of 100 years refer to the amount of time that passes on average (100 years) between consecutive events of similar magnitude. RP100 was chosen for this study, among other reasons because it ensures the variability and representativeness of the results, especially as it is a source that facilitates reproduction in other contexts because of its spatial cover level.

In this case, the human factor is represented by the road transport network. The researchers used the Cartociudad project [33], although it is also common to use Open Street Map [34,35]. For Spain, the Cartociudad method is more precise because it draws on information provided by official sources of 
the National Geographic Institute (IGN), The Land Registry (DGC), National Institute of Statistics (INE) and the Post Office (all abbreviations in Spanish). This cartography of the Spanish road network breaks down the information into road types. The categories considered in the study area are summarized in Table 1.

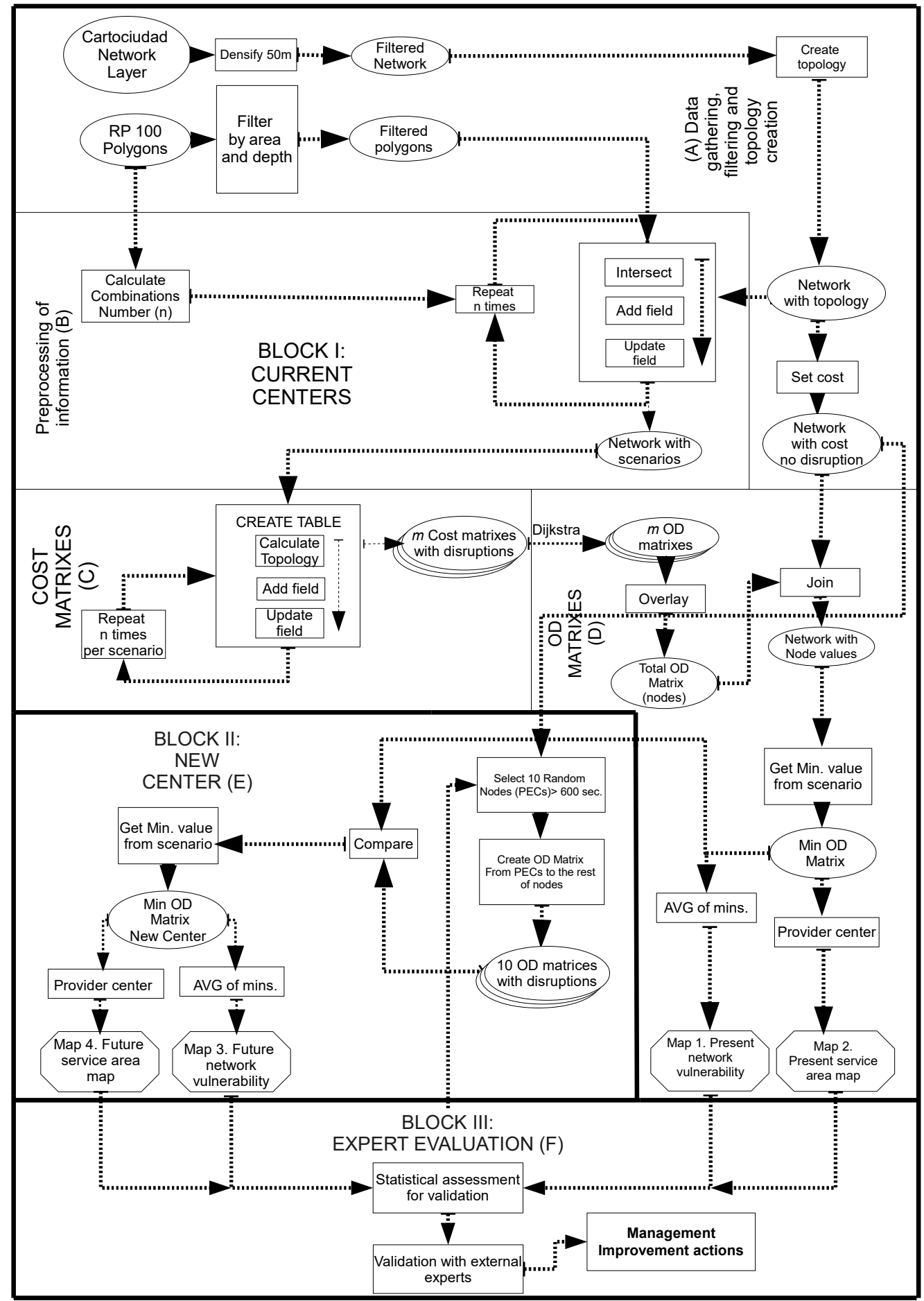

Figure 1. Conceptual scheme of the work carried out. Flow line connectors show the direction that the process flows; Rectangles show spatial instructions or actions; Ellipses show partial results, and are the input information of the next process; as a result, octagons show final maps. 
Table 1. Categories of roads considered in the study area.

\begin{tabular}{cc}
\hline Road Type & Length $\mathbf{( k m )}$ \\
\hline Primary road & 345.3 \\
Secondary road & 114.2 \\
Tertiary road & 147.2 \\
Street & 1097.4 \\
TOTAL & 1704.1 \\
\hline
\end{tabular}

\subsection{1. (A) Data Gathering, Filtering and Topology Creation}

Once the information requirements have been identified, the first step in (A) is to filter the vector files of the road network (using PostgreSQL) and flood-prone areas. In the first case, despite the excellent quality of this type of file in areas such as those selected in the case study, two problems commonly arise:

- The first problem relates to the length of the vectors that usually configure the road layer. The lines corresponding to primary roads are usually too long, which diminishes the spatial resolution and impoverishes the cartography results. For this reason, the network must be segmented into stretches of $50 \mathrm{~m}$.

- This type of network cartography usually lacks topological structure, while its generation usually involves adding spatial information to the road network, such as the relations existing between the different elements. To do this, the researchers used PgRouting as network manager. PgRouting is an extension for PostGIS which allows analyses based on topological networks using SQL. By means of the PgRouting function pgr_createTopology we attach topology to the network. With this process, a table of roads with the created topology is obtained and another of nodes (Network with topology in Figure 1), both used as entry parameters for the vulnerability network analysis.

Once the above is solved, the researchers calculate and assign a cost to each section. The concept of cost in this type of study implies that using the road network is not free and is calculated by reference to the cost unit adopted. Several types of cost can be distinguished (financial, political, etc.), the most common being the time needed to move from the point of origin to a destination [9]. In the present work, we use the time lost in seconds to pass road network section according to the following equation:

$$
C_{t}=\frac{L}{v \cdot(100 / 360)}
$$

where $C_{t}$ is the cost in terms of time (seconds) in passing a section $t, L$ the length of the section $t$ in meters and $v$ the velocity or speed in $\mathrm{km} / \mathrm{h}$.

The speed will vary with the type of vehicle and road. In this case, since emergency services are the users of the network, the researchers consider the mean speed as being $\approx 20 \%$ above the maximum speed permitted for each road type, and take into consideration the characteristics of the types of vehicle that usually take part in rescue missions [36]. Table 2 shows the speeds used in the calculations.

Incorporating the estimated speed in emergency situations to the road network allows us to obtain the Network with cost non-disruptions for emergency vehicles or those of similar characteristics.

Table 2. Estimated speeds in emergencies used in costs calculations.

\begin{tabular}{cc}
\hline Road Type & Estimated Speed \\
\hline Primary road & 140 \\
Secondary road & 100 \\
Tertiary road & 80 \\
Street & 60 \\
\hline
\end{tabular}


Concerning the spatial information for flood-prone areas with a return period of 100 years (RP100 polygons in the scheme), data treatment focuses on vectorizing and simplifying based on the exclusion criterion of the depth of the water layer and area flooded. In this work, a threshold of $50 \mathrm{~cm}$ or more depth and a surface area greater than $5 \mathrm{~m}^{2}$ covered by water are established as factors that prevent emergency vehicles from passing [37]. The vehicles used by emergency services can pass through a considerable depth of water. However, the most significant problem is not the exhaust pipe since most have a vertical air intake of about 3 meters, but a loss of stability, making it difficult to pass the mentioned thresholds [38]. The polygons below these two values have been excluded from the analysis since they are considered passable by vehicles.

\subsection{2. (B) Preprocessing of Information}

Preprocessing of the spatial data (B) combines the above-treated information, the road network, and flood-prone areas, to calculate the Cost Matrices (C) and OD Matrices (D) between the management centers and the different nodes to the network.

Regarding the calculation of flood scenarios, the parameters necessary to obtain it are the flood zones. All possible scenarios are obtained with a combination without repetition of $k$ items from an $n$ items set, according to the following equation:

$$
C_{n, k}=\frac{n !}{k ! \cdot(n-k) !}
$$

These combinations $\left(C_{n, k}\right)$ represent the number of combinations of different flood-prone areas; these are the different groups of $k$ elements that can be formed by these $n$ elements (flood prone areas), so that two groups differ only if they have different elements. This process has been automated by a script from phyton and QGIS to obtain flood scenarios in vector format.

\subsection{3. (C) Cost Matrices}

The non-disruption network scenario (Network with cost non-disruption) must be related to the combinations of possible floods to obtain network disruption scenarios. This procedure is usually carried out by a simple geoprocess that physically eliminates those sections of the road network that intersect with the disruption [24]. However, because the flood-prone areas usually cut the network into several sectors, the researchers have chosen a more practical solution that facilitates the multiple processing of the cost matrices for each network scenario. In those places where the water level would impede the passage of vehicles, a high cost is assigned to the node affected $(>10,000 \mathrm{sec}$.). So, when the cost of using that particular route is calculated, the section would be considered invalid, and the cost of reaching the next node, preferably using an alternative route, would be calculated. If this were not done, the cost would be excessive, and it would difficult to identify poorly connected or isolated zones. This process is carried out automatically using the spatial functions of PostGIS. Table 3 includes an example to create one of the columns for the flood scenario 1. 
Table 3. example to create one of the columns for the flood scenario 1.

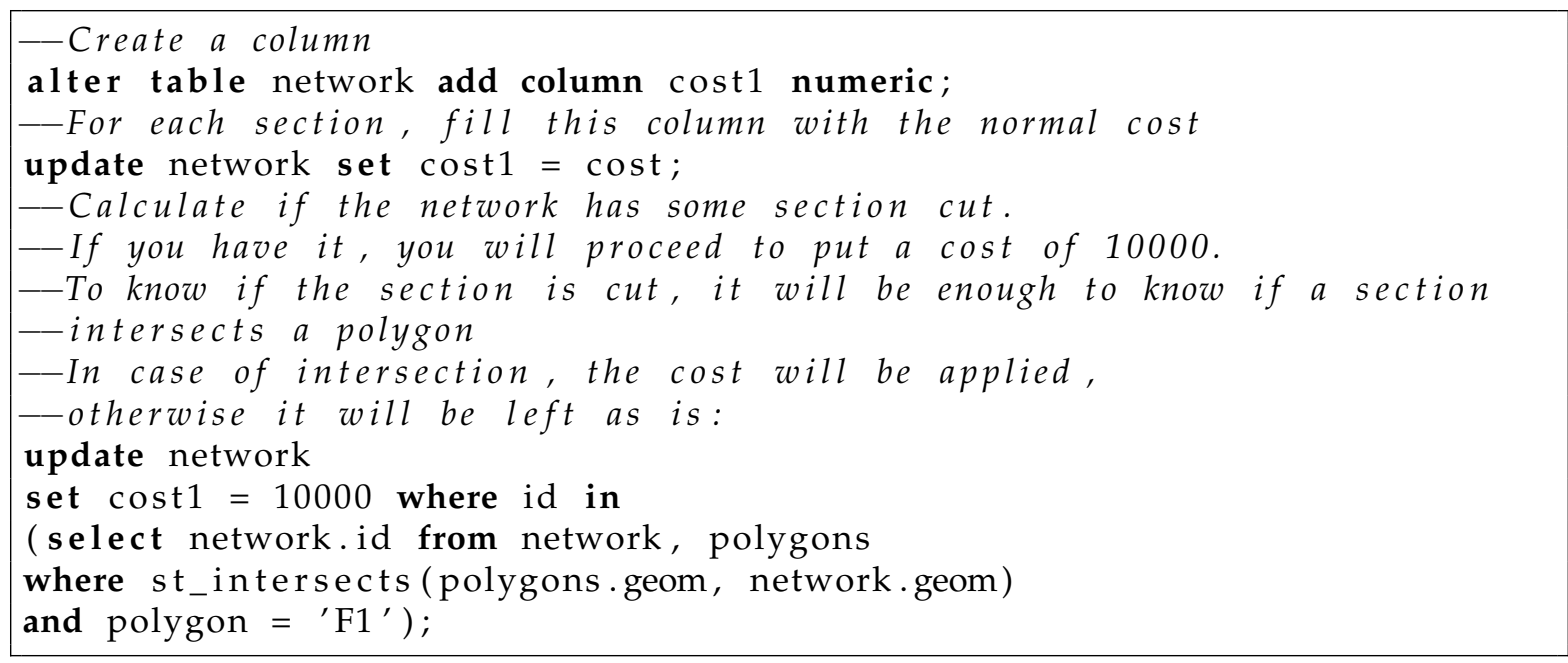

\subsection{4. (D) O-D Matrices}

Once the costs matrices have been calculated, the ODM (D) are obtained with the distances between the different elements of the network. The main objective is to obtain a table of network nodes (destinations) and the accumulated cost (sec.) for a vehicle from every emergency management center (origin, $m$ ). The iterative calculation is made for each costs matrix and emergency management center using PgRouting and the shortest path algorithm, or Dijkstra's algorithm [39]. The theory underlying this algorithm is that all the routes from the point of origin to all other points of destination are explored until the shortest one is found.

The algorithm provides the $m$ ODM in which the costs associated with each emergency center (time taken to reach the different network nodes) are summarized for each network scenario. The $m$ tables are unified by a procedure known as spatial overlay, thus giving Total ODM (nodes) with $n \cdot m$ columns, aare joined to the layer of network nodes Network with cost non-disruptions. From this result, the minimum value for each network scenario (Min ODM) is obtained using PostGIS. This database manager let us identify which management center get to first and faster to a particular node of the network (Figure 2).

The above process of Block I terminates with map 1 Present network vulnerability (Figure 5) from the mean of the Min ODM for each point and network scenario thus providing the integrated vulnerability value in one table (Mean minimum column, Figure 2). This map will show the minimum mean access to each node (accessibility increases as the cost of reaching the destination node decreases). The vulnerability results allow map 2 to be constructed for each control center, Present service area map (Figure 9a). The maps represent the control center that will reach each scenario more frequently and faster and identify the center's immediate field of action and where it is preferable for a vehicle from another center to attempt to do so.

This process is similar to the previous one, but instead of selecting the minimum cost associated with the destination node, the researchers use the one associated with each emergency center. 


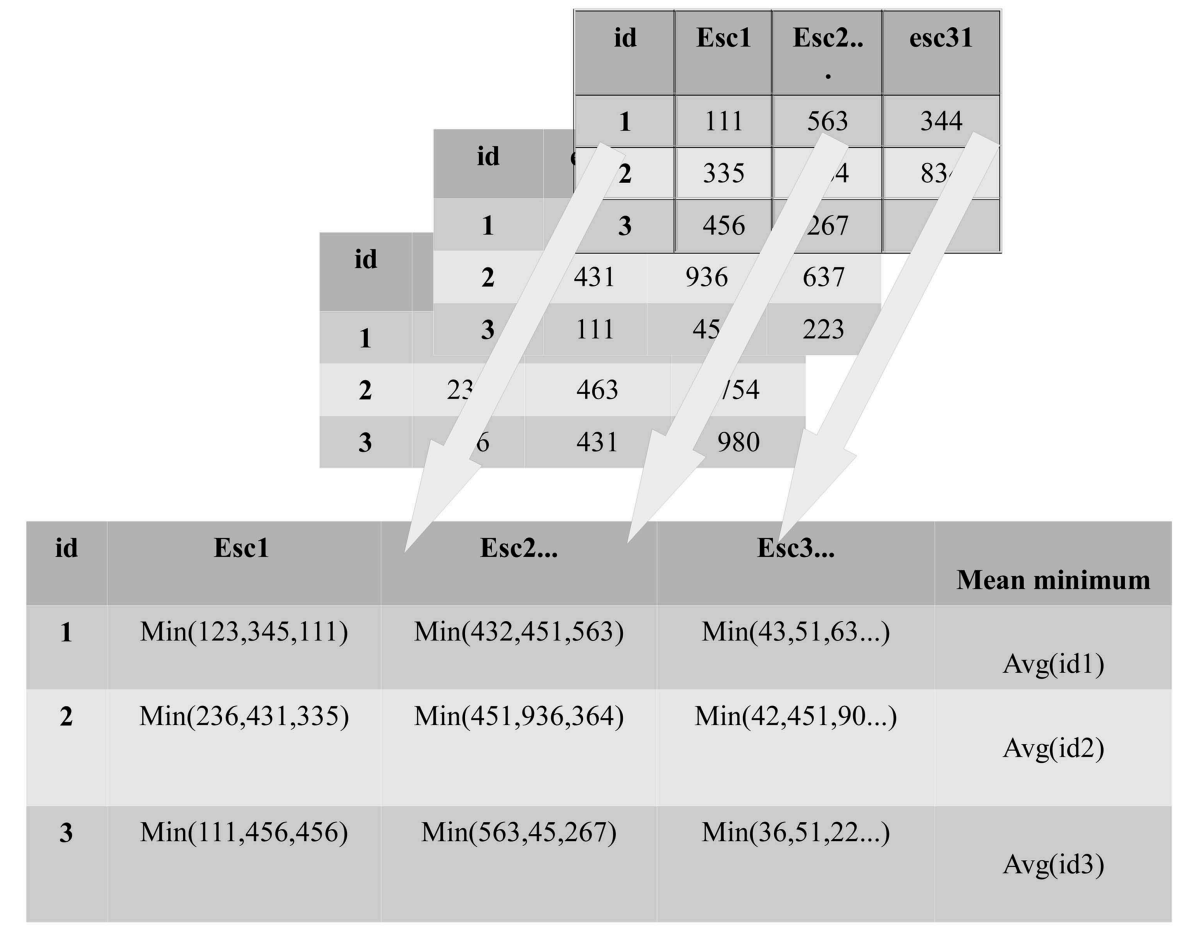

Figure 2. Process for constructing the table of means of the minimum times. Example for the case study ( $n=31$ scenarios and $m=3$ emergency centers).

\subsection{Block II: Optimal Location of New PEC}

The second block aims to identify possible optimal sites (nodes in the road network) to build a PEC, which will reduce the vulnerability of the network in terms of costs (time to reach all nodes). The procedure to identify this PEC in the road network is summarized below:

1. Identification of candidate PEC. Ten possible nodes for locating the PEC are chosen for computational purposes. The points selected must satisfy the following criteria: the journey cost or response time from the existing emergency control centers to these new points in a normal situation (with no flooding) must not be more than $600 \mathrm{~s}$, which is the minimum response time usually considered in the bibliography on optimal localizations [40]. This will ensure that the optimal location of PEC will not be excessively close to one of the three existing centers. It is, therefore, understood that the spatial distribution will affect (but will not determine) the new site.

2. Calculation of ODM from the selected nodes to the rest of the nodes of the network for every flood scenario. As an example, in the study case, the result gives ten matrices with the dimensions $(1 \times 31$; center/network scenarios) for each possible location of PEC. The matrices depict the costs (time from each node selected to destination nodes) for each network scenario. These ten matrices, one for each new PEC, are compared with the Min ODM for block I. In this way, the results for the new points will have been compared with the minima obtained in block I. If the new time taken to arrive at the same destination exceeds the previous minimum, the previous time remains, and if the response time from the new center is improved, the cost of the new one is added. This procedure is very similar to that depicted in Figure 2, which, on this occasion, is repeated ten times (once for each candidate).

3. Once the previous calculations have been made, the mean access times are compared in order to identify the optimal location of the new PEC, selecting the candidate that minimizes this time. This process is based on a statistical hypothesis test (one-way ANOVA). To evaluate the statistical requirements of normality and homoscedasticity necessary in this type of parametric test, Kolmogorov-Smirnov's test for more than 50 cases [41] and Levene's test were used [42]. If these requirements are not met, a robust version of one-way ANOVA using trimmed means 
and Welch correction is used [43]. When the ANOVA F-test is significant, a post hoc analysis is carried out using linear constraints for multiple comparisons, based on T3 Dunnet's method [43].

4. Once the optimum point in terms of time has been identified statistically, the means of the minimum network scenarios for each center, including the new center (PEC), are calculated. By proceeding iteratively for each node selected, the vulnerability value of the network for the existing centers concerning the candidate center is obtained. To evaluate differences in access time in the new scenario, the current network scenario and the future scenario (based on a new PEC) are compared using a robust t-test for repeated measurement based on trimmed means [43].

5. Finally, maps 3 (Future network vulnerability) and 4 (Future service area) are constructed (Figure 9a,b). Map 3 is made in a similar way to map 1, that is, with the results of the mean of the minima of the table Mean ODM New. Map 4 is made like map 2 that is, selecting center name instead of cost.

\subsection{Block III: Expert Evaluation}

Once the results are obtained, the third block defines the process of validation and evaluation of the results. This block is outside the implemented process but is essential because it involves the agencies responsible for emergency management. This section includes the decisions that must be taken to solve the problems involved in the new PEC as a function of factors that were not included in the above process (such as suitability as a function of the cadastral value, decisions related with the final management, etc.).

\section{Study Area}

The analysis process proposed in this study was carried out in the urban and suburban setting of Murcia, Alcantarilla, Santomera, and Beniel municipalities, in south-eastern Spain (Figure 3). It is an area featured with severe flooding problems due to the sometimes extreme behavior of the hydrographic network that drains it [44].

Flood-prone areas of the study area are characterized by a large number of wide riverbeds that, in flood situations, would interrupt the road network, and which must be taken into account when calculating possible scenarios. To simplify such calculations without losing information in the process, the riverbeds can be grouped based on topography. Five zones were considered as flood prone area scenarios (Figure 4): Segura river, Guadalentin river, North area (Ramblas draining the northern slopes), South area (Ramblas draining the southern slopes) and Northeast area (Ramblas draining the north-eastern slopes). As a result of Equation (2), 31 possible scenarios were obtained in the study area by combining the five possible flood zones that were summarized in the Network with scenarios.

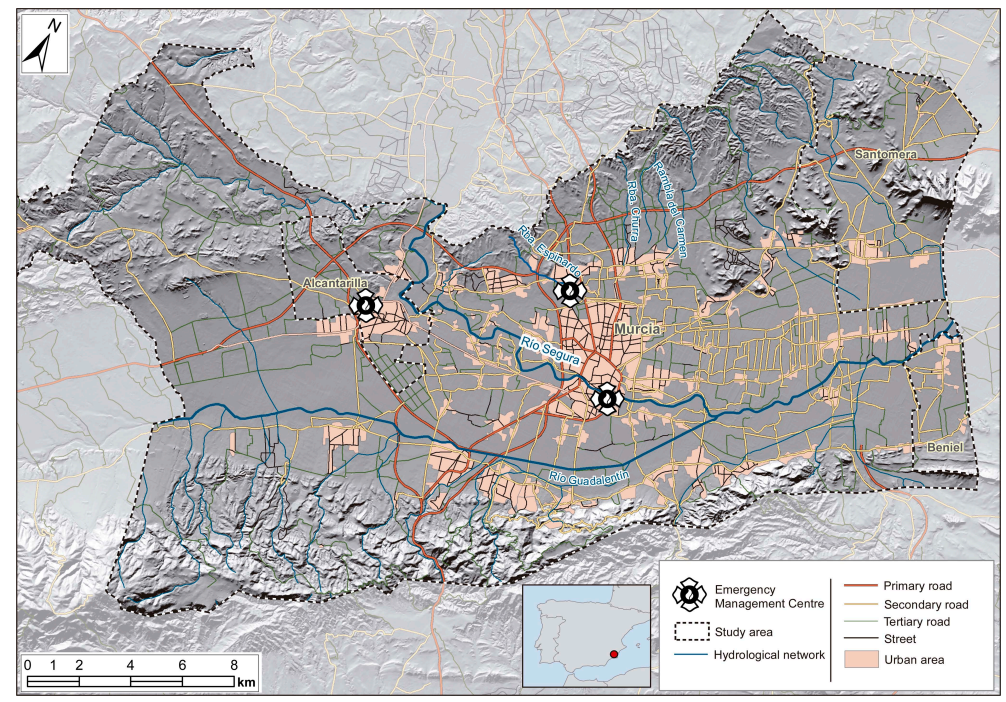

Figure 3. Study area including urban area, road network, and emergency management centers. 


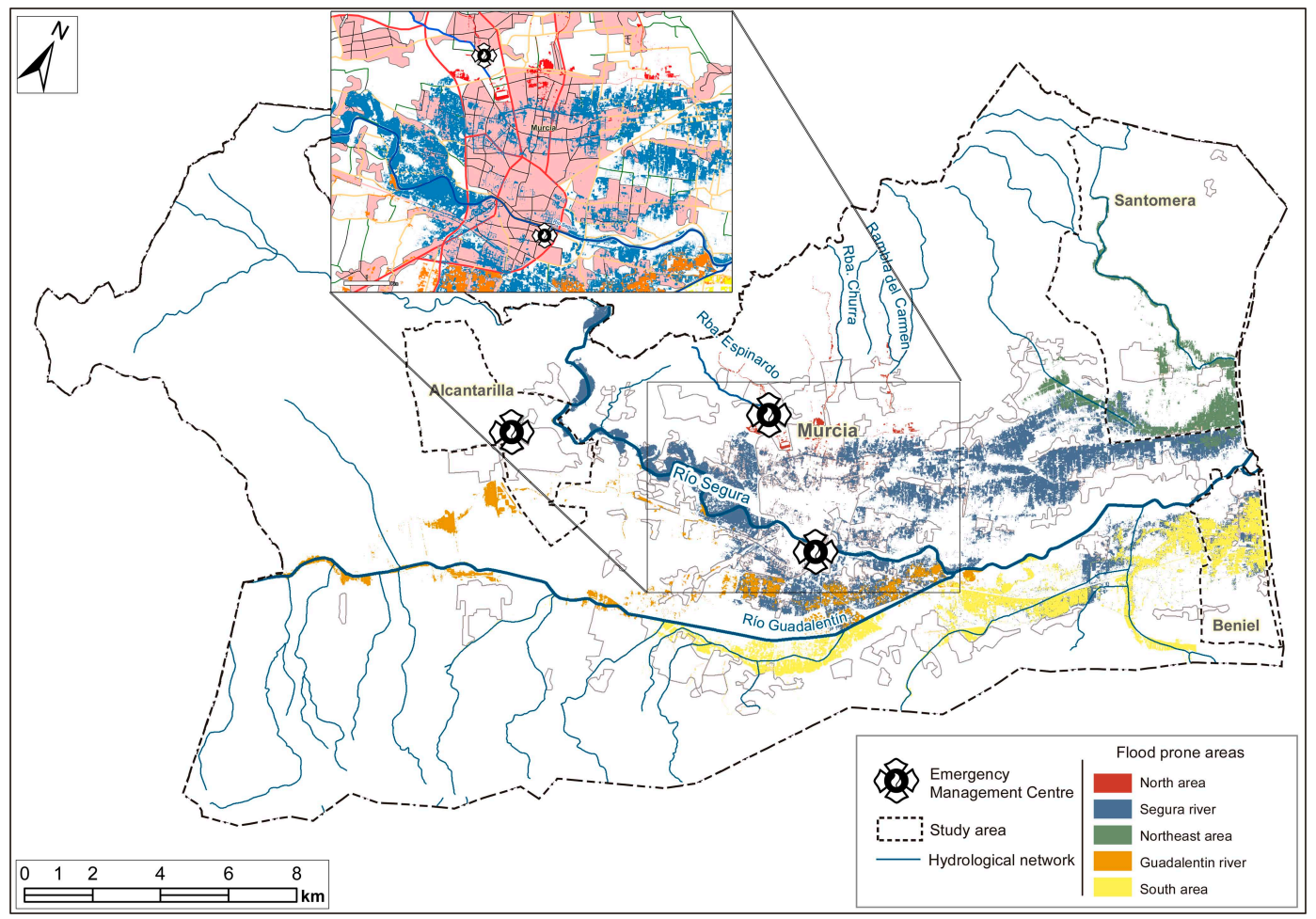

Figure 4. Flood-prone areas scenarios.

The road network is characterized by its high density and, in general, extends over the river beds that drain the area. As a result of channeling, the two main rivers that drain the area, the Guadalentin and Segura, have remained mostly unaffected by urban development and the road network crosses them using bridges. The danger that represents these two rivers comes from overflow. However, the other waterways (the Ramblas or ephemeral streams, which mostly follow a rectilinear path) have been occupied or, in some instances, incorporated into the road system. As a result, every time one or several of these streams flood, the problems of accessibility between the road network's points are exacerbated.

Concerning its morphometric characteristics (Table 4), the network is divided into 21319 sections of differing hierarchical importance, making a total of $1704.4 \mathrm{~km}, 82 \%$ of which are in the municipal area of Murcia, although the highest density is in Alcantarilla, where urban growth and the increase in the number of inhabitants emphasizes the development that has taken place in an area of reduced dimensions. The ratio between road kilometers and several inhabitants is the opposite of that in Santomera.

Table 4. Morphometry of the network in the study area.

\begin{tabular}{lllllllll}
\hline Municipality & $\begin{array}{l}\text { Area } \\
\left(\mathbf{k m}^{2}\right)\end{array}$ & $\mathbf{\%}$ & Population & $\mathbf{\%}$ & $\begin{array}{l}\text { Length } \\
\mathbf{( k m}^{2} \mathbf{)}\end{array}$ & $\mathbf{\%}$ & $\begin{array}{l}\text { Density } \\
\left(\mathbf{k m} / \mathbf{k m}^{2}\right)\end{array}$ & $\begin{array}{l}\text { Road } \\
(\mathbf{N e t} / \text { /Pop.) }\end{array}$ \\
\hline Alcantarilla & 16.241 & 3.25 & 41,406 & 8.39 & 117.919 & 6.92 & 7.26 & 2.85 \\
Beniel & 10.092 & 2.02 & 11,057 & 2.24 & 27.041 & 1.59 & 2.68 & 2.45 \\
Murcia & 429.804 & 85.91 & 425,465 & 86.22 & 1469.677 & 86.23 & 3.42 & 3.45 \\
Santomera & 44.174 & 8.83 & 15,547 & 3.15 & 89.768 & 5.27 & 2.03 & 5.77 \\
Total & 500.311 & 100 & 493,475 & 100 & 1704.405 & 100 & & \\
\hline
\end{tabular}

It should be pointed out that the whole population of the municipalities conforming the study area is served by three main emergency response centers. (i) Espinardo, responsible for the northern zone of the city of Murcia,(ii) Infante, responsible for the southern zone on the right bank of the river Segura, and (iii) Alcantarilla, which serves the municipality of the same name and part of the western 
zone of Murcia. The equipment and manpower of each of the centers are roughly equal, although Infante has traditionally had a slight advantage in this respect.

\section{Results}

\subsection{Present Road Network Vulnerability Map}

The map in Figure 5 summarizes the results of the network vulnerability analysis concerning displacements (measured in seconds) for the three centers that are operational at present. Two main points are evident. First, there is a concentration of road interruptions in the north and south of the city of Murcia and the north-east of the study area, in the municipalities of Santomera and Beniel. These areas, which have the highest values (yellow, orange, and red), are frequently the most difficult to reach in terms of time, due to breaks in the road network. They are, therefore, the most sensitive, and it is here that the road network needs particular attention. Second, there are two possible ways of improving the situation.

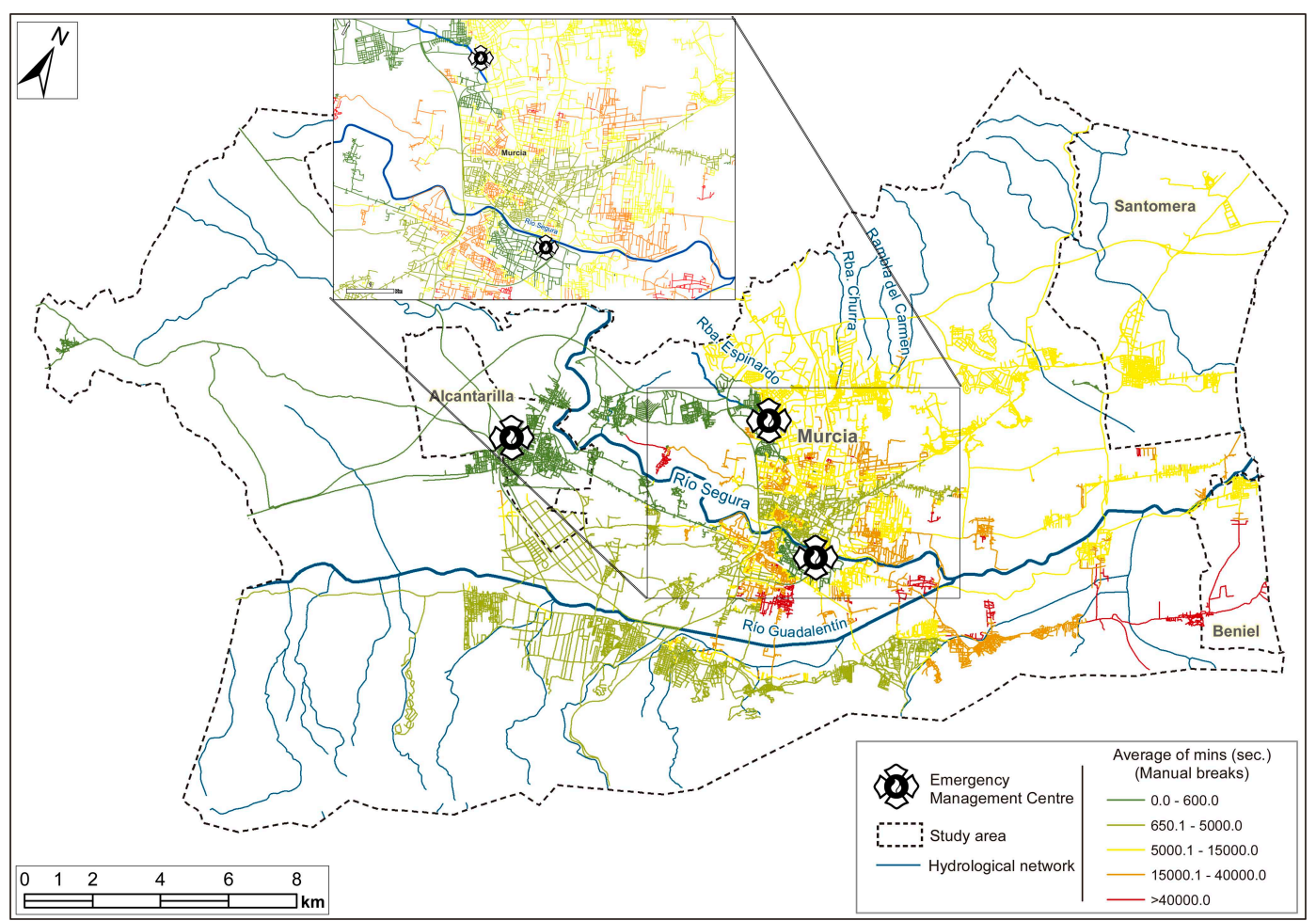

Figure 5. Map of present network vulnerability.

In the city of Murcia, structural initiatives are recommended (controlling flooding or providing alternative itineraries in the north and south). However, in the eastern part of the study area, there is no immediate response to an emergency situation since it is far from the existing emergency management centers, making it the prominent site for a new PEC.

\subsection{Vulnerability of Future Network Following the Optimal Siting of a New Command Center}

An analysis of the variance based on the Welch correction was carried out to identify the point that reduces the vulnerability of the network to the greatest extent. The results obtained indicated that the optimal point had a significant effect on access in time $(F(9,51598)=42.347, p<0.0001)$. Figure 6 depicts the mean access time (arithmetic and trimmed means) in increasing order by interval and homogeneous groups derived from the lincon post hoc test. The groups concentrate network scenarios whose $\mathrm{p}$ values infer that the mean access time is not significantly different; for example, the network scenarios of the group (a) will not differ significantly among themselves and will involve significantly 
higher mean access times than those included in group (b). The group representing the shortest access time is group $(\mathrm{d})$, which includes network scenarios $1(M=8030, C I=179)$ to $6(M=8263, C I=190)$, with no significant difference between them in terms of mean access time, which can be regarded as optimal since the access time is lower than for the rest of the network scenarios. From network scenario $7(M=8506, C I=185)$, the access times are considered significantly different from the times of the network scenarios of group $d$ ).

Having decided on the best location for the new PEC (selected node 1), the vulnerability of journeys is evaluated once again with all four centers. Figure 7 points to a statistically significant reduction in the mean access time $(T(17056)=56.877, p<0.0001)$. The results represented cartographically in Figure 8a shows an improvement over those obtained for the present vulnerability map.

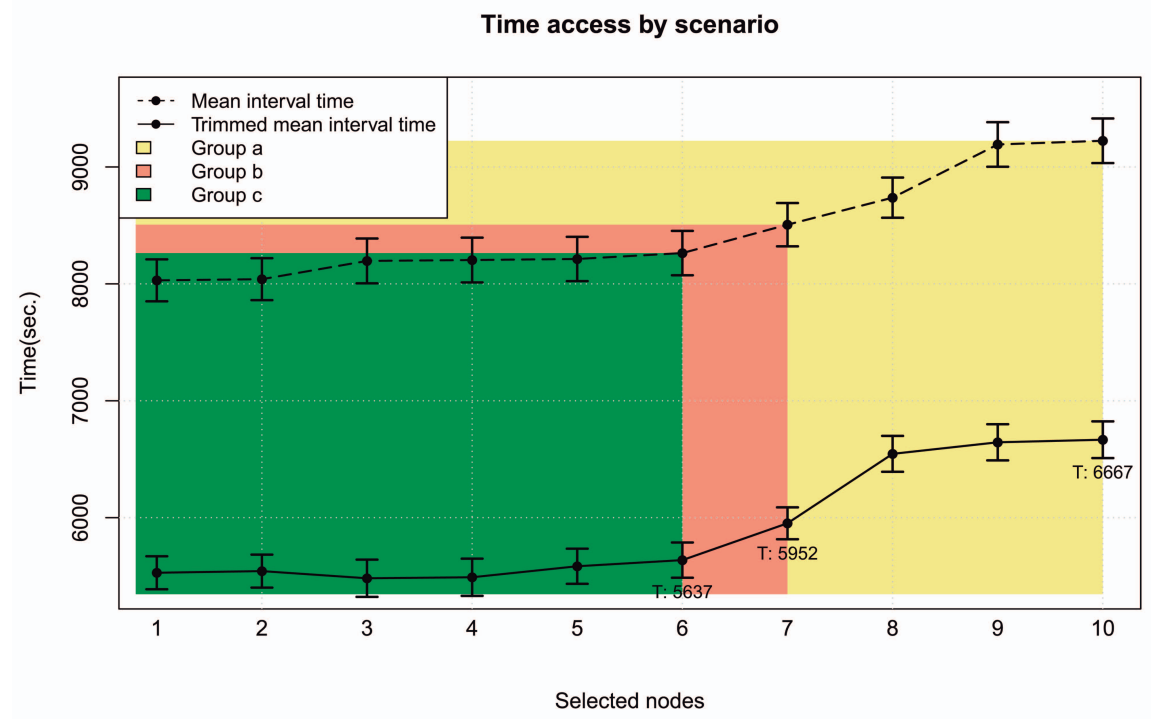

Figure 6. Mean access time (arithmetic and trimmed means) for each new PEC and scenario. Main effects, selected nodes factor (mean and 95\% confidence interval). Means with different letters (rectangles) are significantly different (lincon multiple comparisons, $p<0.05$ ).

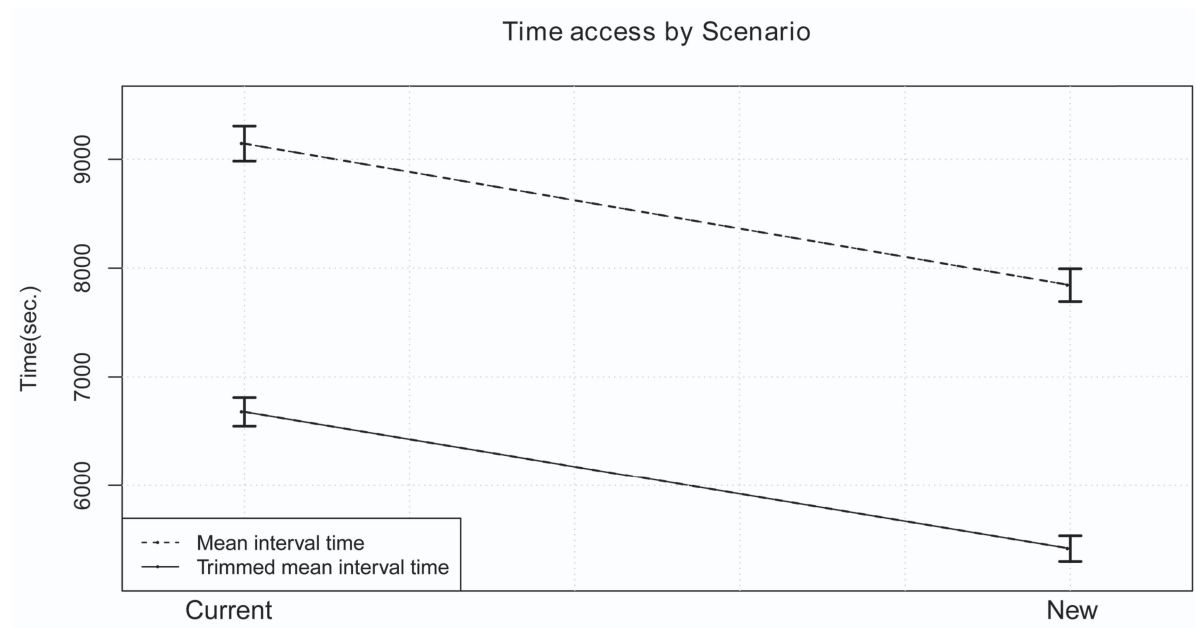

Figure 7. Main effects, network scenario factor (mean and $95 \%$ confidence interval). Effects in terms of diminution in mean time (arithmetic and trimmed means) of present network vulnerability and future network vulnerability. 
Other issues are worth mentioning, too. First, despite the reduced vulnerability, high values are still obtained for subnetworks of the hub and spoke type [45], which remain highly vulnerable since they are frequently affected and represent a loss of operational efficiency in this zone (in red in Figure $8 \mathrm{a}, \mathrm{b})$. This type of isolated areas can be observed to the south and southeast of the Infante station and in the network, sections corresponding to the municipality of Beniel, where high-cost values are due to the interruptions caused by two or three flood-prone zones in critical sections. The first case is of note because of the proximity in Euclidean distance to the control center, which underlines the need for this point to be secure.

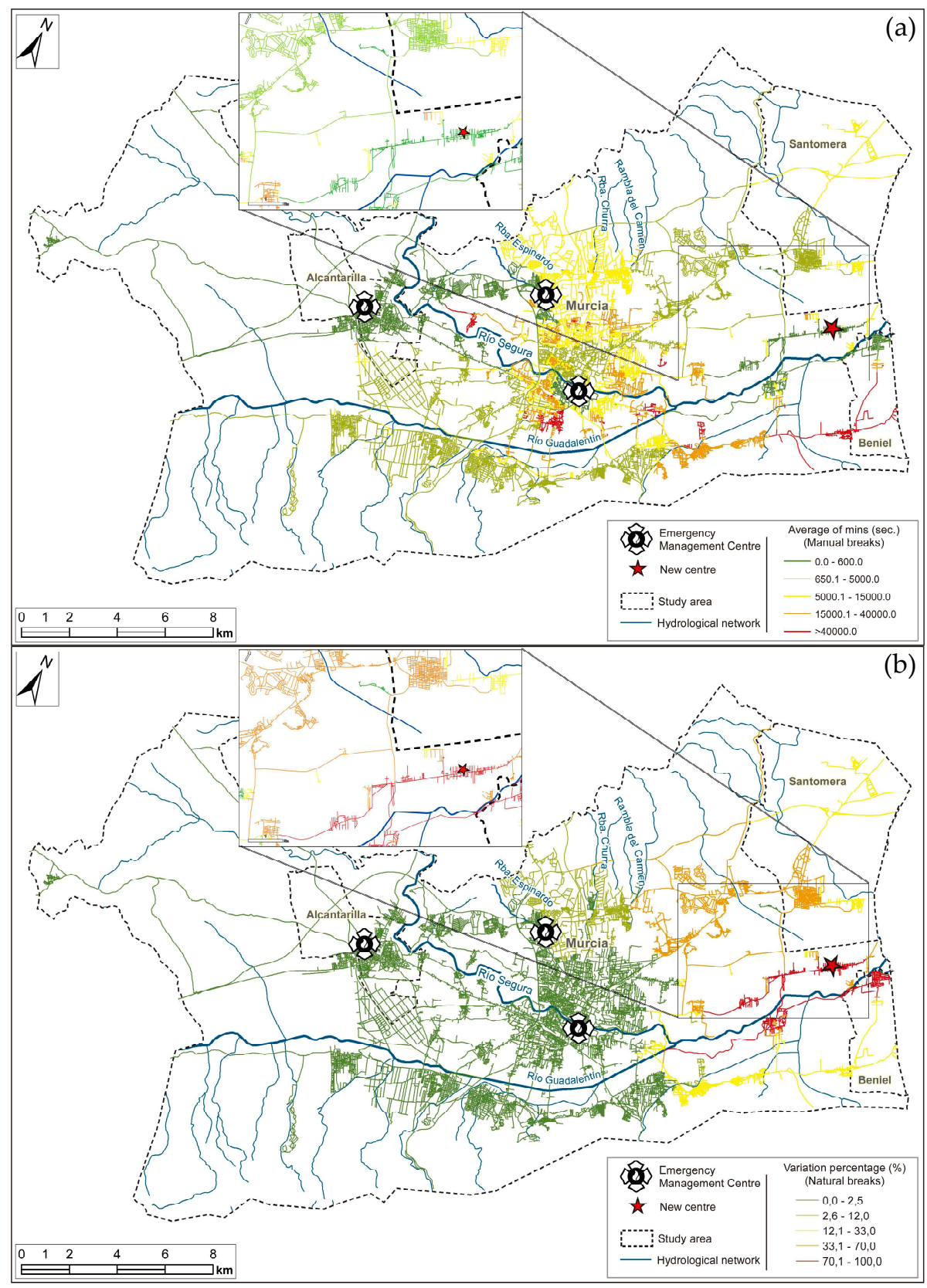

Figure 8. (a) Maps of future vulnerability scenarios; (b) Percentage of variation.

Secondly, interpretation of the map helps reveal the least and most suitable locations for the control centers. The best example of the first is represented by the Espinardo center, whose location on the road coinciding with a river flood bed substantially limits eastward journeys; in this case, the 
PEC would slightly alleviate the problem, as can be seen in Figure $8 b$. With regard to optimal sites, the existing Alcantarilla center serves a wide zone since its radius of action is not affected by interruptions.

\section{Discussion}

The cartography corresponding to emergency service areas allows us to discuss the results obtained. In maps of Figure 9a,b, the researchers identify the sections of the network that can be accessed more quickly and frequently by a control center. From a comparison of both figures, it can be seen that the method followed to find the optimal location of the PEC has made it possible to equally distribute the centers spatially. On the other hand, quantitative analysis of the differences in values between both maps depicted in Table 5 suggests that the above-mentioned improvement has mainly been produced in the sections served by Espinardo center, whose service area is reduced by $45.8 \%$. This is followed by the Infante center, with only $9.5 \mathrm{~km}$ difference (1.2\%). For its location concerning the PEC, Alcantarilla remains unchanged. As a whole, the new center represents an accessibility gain of $16.4 \%$ concerning the current vulnerability network.

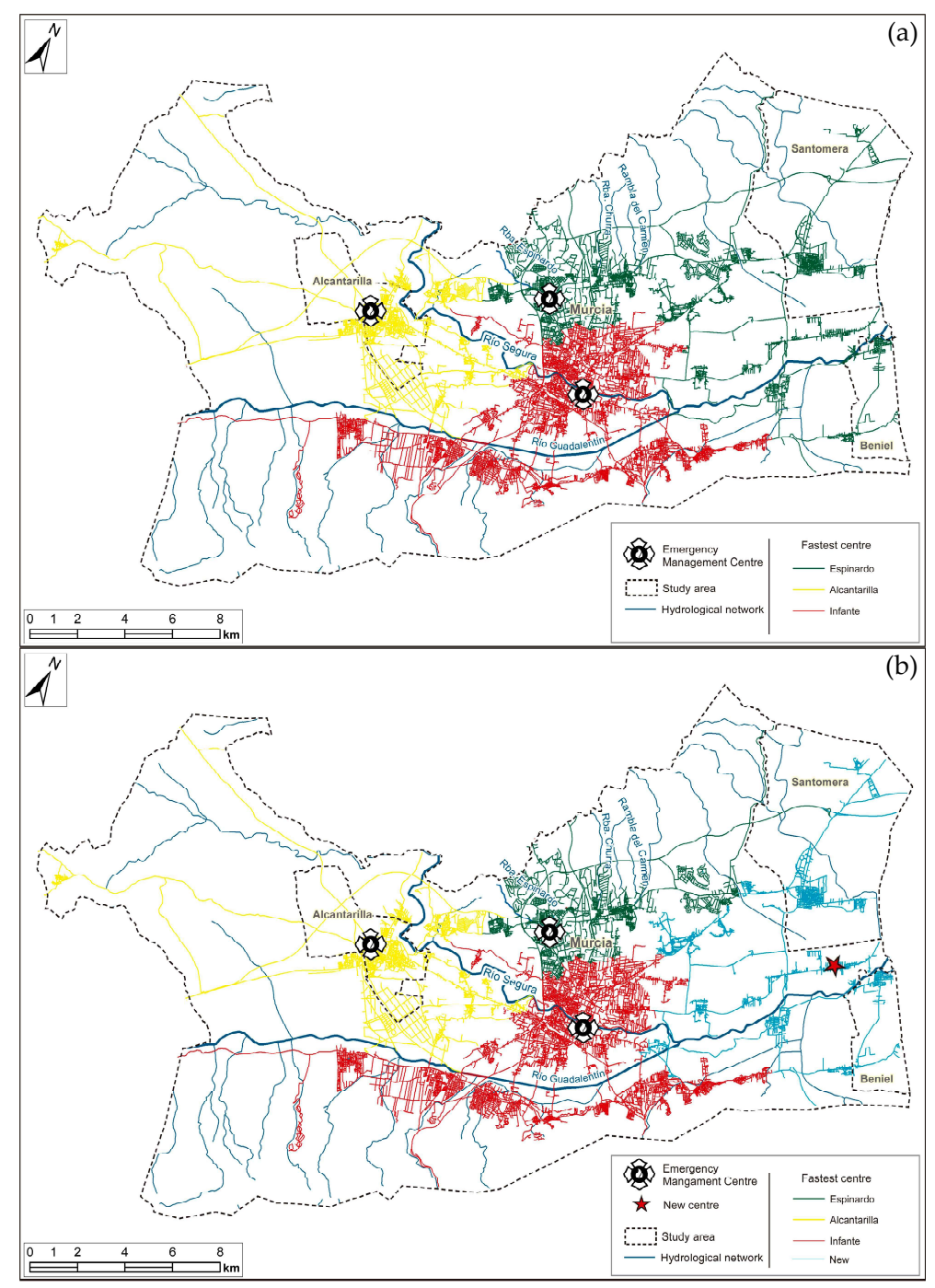

Figure 9. (a) Map of the service areas in the current vulnerability network and (b) with the new center. 
Table 5. Results obtained with the lengths of the sections with the new center included, and difference concerning the present situation.

\begin{tabular}{|c|c|c|c|c|c|c|}
\hline $\begin{array}{l}\text { Center } \\
\text { (Node) }\end{array}$ & $\begin{array}{l}\text { Present Network } \\
\text { Length Emergency } \\
\text { Service Area (km) }\end{array}$ & $\begin{array}{l}\%(100=\text { Total } \\
\text { Network })\end{array}$ & $\begin{array}{l}\text { Length Emergency } \\
\text { Service Area with } \\
\text { New Center (km) }\end{array}$ & $\begin{array}{l}\%(100=\text { Total } \\
\text { Network })\end{array}$ & $\begin{array}{l}\% \text { of Variation }(100= \\
\text { Present Emergency Service } \\
\text { Area) }\end{array}$ & $\begin{array}{l}\text { Difference }(\mathrm{km}) \\
\text { (Present-New } \\
\text { Center) }\end{array}$ \\
\hline $\begin{array}{l}\text { Espinardo } \\
\text { (1006) }\end{array}$ & 591.2 & 34.6 & 320.1 & 18.8 & -45.8 & 271.1 \\
\hline $\begin{array}{l}\text { Alcantarilla } \\
\text { (1304) }\end{array}$ & 324.8 & 19.0 & 324.8 & 19.0 & 0 & 0 \\
\hline Infante (6050) & 788.1 & 46.2 & 778.6 & 45.7 & -1.2 & 9.5 \\
\hline New (9700) & 一 & - & 280.6 & 16.4 & - & - \\
\hline Total & 1704.1 & 100 & 1704.1 & 100 & -16.4 & 280.6 \\
\hline
\end{tabular}


Despite the improvements that represent the installation of a new center, there are still some road sections with substantial problems of isolation in flood situation. These results are consistent with those obtained by other works that use graph theory through SIG $[5,15,34,46]$. Given this circumstance and given that the problem of flooding could be increased taking into account the projections of climate change and increased exposure [47], this type of methodologies could lead to an improvement in efficiency in transport policies focusing his efforts in the reinforcement of these, especially critical sections.

This type of actions tends to focus on high-capacity roads as they are critical elements of the network due to a large amount of traffic they channel [48]. However, in the case of emergency management, it is also essential to highlight the importance of individual sections that, even with little traffic, are critical for some localities, especially when there are hardly any alternative routes because they are spaces with very low network density, which is common in peri-urban areas or mountain areas [49]. From the above, it can be inferred that vulnerability analysis of the networks provides information of interest, both in management tasks and in transportation planning.

On the other hand, there are still informational deficiencies and possible improvements that could be made: for example, with regard to the vulnerability analysis, considering the workflow of the physical state of the road or the average amount of traffic of each section to improve the calculation of the cost; in this context, with suitable information regarding roads and the volume of traffic, cost calculations can be modified simply by including the BPR (Bureau of Public Roads) formulation [50] for estimating link resistance and travel time. About the location procedure, the weaknesses of the proposed methodology could be improved through multi-criteria analysis techniques [51,52]. In this sense, the methodology proposed works with ten nodes (the available spaces with which municipal authorities in spatial planning usually deal). However, such decisions may be influenced by the needs of the population, which would carry more weight in justifying the new location rather than distances, costs, and isolation of the network's nodes. These are new challenges that open up the possibility of improving this type of study.

Once the above limitations have been overcome, the method can be used and replicated perfectly in other areas of study following the standardized procedure that summarizes the scheme of Figure 1. However, the only difficulty to carry out the above would be related to the issues of boundary conditions. In the case of this study, those limits are marked by orography, however, in other cases where the method is applied, this maybe very dificult.

\section{Conclusions}

According to the latest reports of the intergovernmental panel on climate change, there are still significant gaps in knowledge about the possible impacts that climate change may have on transport systems. Some relevant studies $[53,54]$ outline some of the vital research needs and challenges. At the local scale, climate projections models that incorporate unique attributes of the urban transportation system are lacking. However, downscaled assessment is a prerequisite for a transportation planner to identify facilities and locations that are vulnerable to the impacts of climate-related events like floods.

At this sense, the proposed methodology provides two leading solutions for urban policymakers. First, a map of the present network vulnerability informs about critical network sections that should be reinforced or protected to facilitate population evacuation and the movement of emergency teams in case of catastrophe. Second, when these adaptation measures are not to be carried out, solutions, like finding the optimum location for a new PEC based in terms of reduced travel time to reach the rescue points seems, could be the best ones to solve that gap. To reduce subjectivity in that decision, the proposed method enhanced the procedure with the cartographic and statistical results of the current network's vulnerability developed in the first solution. Results of the present work show that a new emergency management center reduces present vulnerability and compensates the deficiencies in the service areas of other stations, mainly those who, due to their location, are severely restricted in their action by the presence of riverbeds, such as what occurs in Espinardo in the case of a recent 
study. Despite the advantage that the new station presents, there are two types of network sections whose vulnerability is not reduced. First, those in which several flood-prone areas converge. In those cases, although there is a center close to them in terms of Euclidean distance, accessibility problems are not solved since many of the sections that give access are affected. Such situations can be seen in the study area in the municipal district of Beniel and south Murcia. Second, there are also other specific examples in which the connection to the leading network depends on one connection that is frequently affected by more than one flood zone, so they are quickly isolated. One of these is to the west of Murcia. As mentioned above, to solve these problems, actions of a preventive nature, such as planning, do not fit well, and decisions are forced to go through structural actions.

Author Contributions: Conceptualization, A.P.-M., F.G.-C. and P.P.-Z.; Data curation, A.P.-M. and P.P.-Z.; Formal analysis, A.P.-M. and F.G.-C.; Funding acquisition, A.P.-M.; Investigation, A.P.-M., F.G.-C. and P.P.-Z.; Methodology, A.P.-M., F.G.-C. and P.P.-Z.; Software, A.P.-M., F.G.-C. and P.P.-Z.; Validation, P.P.-Z.; Visualization, A.P.-M. and F.G.-C.; Writing—original draft, A.P.-M., F.G.-C. and P.P.-Z.; Writing—review \& editing, A.P.-M. and F.G.-C.

Funding: This research was funded in part by the Ministerio de Economía, Industria y Competitividad, Gobierno de España, grant number CGL 2016-75996-R, project Variabilidad espacio-temporal de las inundaciones en la cuenca mediterránea española desde 1300 A.D.: procesos atmosféricos, hidrológicos e interacciones con la actividad humana.

Conflicts of Interest: The authors declare no conflict of interest.

\section{References}

1. Hunt, A.; Watkiss, P. Literature Review on Climate Change Impacts on Urban City Centres: Initial Findings; OECD: Paris, France, 2007.

2. Board, T.R.; Council, N.R. Potential Impacts of Climate Change on U.S. Transportation: Special Report 290; The National Academies Press: Washington, DC, USA, 2008.

3. Mehrotra, S.; Lefevre, B.; Zimmerman, R.; Gerçek, H.; Jacob, J.; Srinivasan, S. Climate change and urban transportation systems. In Climate Change and Cities: First Assessment Report of the Urban Climate Change Research Network; Rosenzweig, C., Solecki, W., Hammer, S., Mehrotra, S., Eds.; Cambridge University Press: Cambridge, UK, 2011; pp. 145-177.

4. Berdica, K. An introduction to road vulnerability: What has been done, is done and should be done. Transp. Policy 2002, 9, 117-127. [CrossRef]

5. Rodríguez Núñez, E.; Gutiérrez Puebla, J. Análisis de vulnerabilidad de redes de carreteras mediante indicadores de accesibilidad y SIG: Intensidad y polarización de los efectos del cierre de tramos en la red de carreteras de Mallorca. GeoFocus. Revista Internacional de Ciencia y Tecnología de la Información Geográfica 2012, 12, 374-394.

6. Jenelius, E.; Mattsson, L.G. Developing a Methodology for Road Network Vulnerability Analysis. In Proceedings of the Nectar Cluster 1 Seminar, Molde, Norway, 12-13 May 2006, pp. 1-9.

7. Taylor, M.A.P.; Sekhar, S.V.C.; D’Este, G.M. Application of Accessibility Based Methods for Vulnerability Analysis of Strategic Road Networks. Netw. Spat. Econ. 2006, 6, 267-291. [CrossRef]

8. Chen, B.; Lam, W.; Sumalee, A.; Li, Q.; Zhi-Chun Li, Z.C. Vulnerability analysis for large-scale and congested road networks with demand uncertainty. Transp. Res. Part A Policy Pract. 2012, 46, 501-516. [CrossRef]

9. Mattsson, L.G.; Jenelius, E. Vulnerability and resilience of transport systems-A discussion of recent research. Transp. Res. Part A Policy Pract. 2015, 81, 16-34. [CrossRef]

10. Burgholzer, W.; Bauer, G.; Posset, M.; Jammernegg, W. Analysing the impact of disruptions in intermodal transport networks: A micro simulation-based model. Decis. Support Syst. 2013, 54, 1580-1586. [CrossRef]

11. Chen, X.Z.; Lu, Q.C.; Peng, Z.R.; Ash, J.E. Analysis of Transportation Network Vulnerability Under Flooding Disasters. Transp. Res. Rec. J. Transp. Res. Board 2015, 2532, 37-44. [CrossRef]

12. Jenelius, E.; Petersen, T.; Mattsson, L.G. Importance and exposure in road network vulnerability analysis. Transp. Res. Part A Policy Pract. 2006, 40, 537-560. [CrossRef]

13. Jenelius, E.; Mattsson, L.G. Road network vulnerability analysis of area-covering disruptions: A grid-based approach with case study. Transp. Res. Part A Policy Pract. 2012, 46, 746-760. [CrossRef]

14. Pregnolato, M.; Ford, A.; Robson, C.; Glenis, V.; Barr, S.; Dawson, R. Assessing urban strategies for reducing the impacts of extreme weather on infrastructure networks. Open Sci. 2016, 3. [CrossRef] 
15. Sohn, J. Evaluating the significance of highway network links under the flood damage: An accessibility approach. Transp. Res. Part A Policy Pract. 2006, 40, 491-506. [CrossRef]

16. Badri, M.A.; Mortagy, A.K.; Alsayed, C.A. A multi-objective model for locating fire stations. Eur. J. Oper. Res. 1998, 110, 243-260. [CrossRef]

17. Chevalier, P.; Thomas, I.; Geraets, D.; Goetghebeur, E.; Janssens, O.; Peeters, D.; Plastria, F. Locating fire stations: An integrated approach for Belgium. Soc. Econ. Plan. Sci. 2012, 46, 173-182. [CrossRef]

18. Liu, N.; Huang, B.; Chandramouli, M. Optimal Siting of Fire Stations Using GIS and ANT Algorithm. J. Comput. Civil Eng. 2006, 20, 361-369. [CrossRef]

19. Tzeng, G.H.; Cheng, H.J.; Huang, T.D. Multi-objective optimal planning for designing relief delivery systems. Transp. Res. Part E Logist. Transp. Rev. 2007, 43, 673-686. [CrossRef]

20. Berdica, K.; Mattsson, L.G. Vulnerability: A Model-Based Case Study of the Road Network in Stockholm. In Critical Infrastructure: Reliability and Vulnerability; Murray, A.T.; Grubesic, T.H., Eds.; Springer: Berlin/Heidelberg, Germany, 2007; pp. 81-106.

21. Chen, A.; Yang, H.; Lo, H.K.; Tang, W.H. A capacity related reliability for transportation networks. J. Adv. Transp. 1999, 33, 183-200. [CrossRef]

22. D'Este, G.; Taylor, M.A.P. Modelling network vulnerability at the level of the national strategic transport network. J. East. Asia Soc. Transp. Stud. 2001, 4,1-14.

23. Das, I.; Kumar, G.; Stein, A.; Bagchi, A.; Dadhwal, V.K. Stochastic landslide vulnerability modeling in space and time in a part of the northern Himalayas, India. Environ. Monit. Assess. 2011, 178, 25-37. [CrossRef]

24. Arşik, İ.; Sibel Salman, F. Modeling Earthquake Vulnerability of Highway Networks. Electron. Notes Discret. Math. 2013, 41, 319-326. [CrossRef]

25. Tinkler, K.J. An Introduction to Graph Theoretical Methods in Geography; Geo Abstracts Ltd.: London, UK, 1977.

26. Church, R.L. Location modelling and GIS. In Geographical Information Systems; Longley, P., Goodchild, M., Maguire, D., Rhind, D., Eds.; John Wiley \& Sons: New York, NY, USA, 1999; pp. 293-303.

27. Fiedrich, F.; Gehbauer, F.; Rickers, U. Optimized resource allocation for emergency response after earthquake disasters. Saf. Sci. 2000, 35, 41-57. [CrossRef]

28. Hasnat, M.; Islam, R.; Hadiuzzaman, M. Emergency Response During Disastrous Situation in Densely Populated Urban Areas: A GIS Based Approach. Geogr. Tech. 2018, 13, 74-88. [CrossRef]

29. Obe, R.; Hsu, L. PostGIS in Action, 2nd ed.; Manning Publications: Greenwich, CT, USA, 2015.

30. R Core Team. R: A Language and Environment for Statistical Computing; R Foundation for Statistical Computing: Vienna, Austria, 2018.

31. MAGRAMA. Guía Metodológica Para el Desarrollo del Sistema Nacional de Cartografía de Zonas Inundables; Ministerio de Agricultura, Alimentación y Medio Ambiente: Madrid, Spain, 2011.

32. European Communities. Council Directive 2007/60/EC of 23 October 2007 on the Assessment and Management of Flood Risks; Technical Report; Office for Official Publications of the European Communities: Luxemburg, Belgium, 2007.

33. Más, S.; García, A.; González, A.; Rubio, J.; Velasco, A.; González, J.; Ruiz, C. CartoCiudad: Una apuesta colaborativa de las Administraciones Públicas en el ámbito de los callejeros; XI Jornadas sobre Tecnologías de la Información para la Modernización de las Administraciones Públicas: Zaragoza, Spain, 2010; pp. 6-9.

34. Bono, F.; Gutiérrez, E. A network-based analysis of the impact of structural damage on urban accessibility following a disaster: The case of the seismically damaged Port Au Prince and Carrefour urban road networks. J. Transp. Geogr. 2011, 19, 1443-1455. [CrossRef]

35. Open Street Map Contributors. 2017. Available online: https:// planet.osm.org or https://www.openstreetmap. org (accessed on 18 January 2017).

36. Moriarty, K.D.; Ni, D.; Collura, J. Modeling Traffic Flow Under Emergency Evacuation Situations: Current Practice and Future Directions. In Proceedings of the 86th TRB Annual Meeting, Washington, DC, USA, 21-25 January 2007; pp. 1-13.

37. Conesa-García, C.; García-Lorenzo, R.; Pérez-Cutillas, P. Flood hazards at ford stream crossings on ephemeral channels (south-east coast of Spain). Hydrol. Process. 2017, 31, 731-749. [CrossRef]

38. Martínez-Gomariz, E.; Gómez, M.; Russo, B.; Djordjević, S. A new experiments-based methodology to define the stability threshold for any vehicle exposed to flooding. Urban Water J. 2017, 14, 930-939. [CrossRef]

39. Dijkstra, E.W. A note on two problems in connexion with graphs. Numer. Math. 1959, 1, 269-271. [CrossRef] 
40. Caunhye, A.M.; Nie, X.; Pokharel, S. Optimization models in emergency logistics: A literature review. Soc. Econ. Plan. Sci. 2012, 46, 4-13. [CrossRef]

41. Royston, P. A remark on algorithm AS 181: The W-test for normality. J. R. Stat. Soc. 1995, 44, $287-321$. [CrossRef]

42. Levene, H. Robust tests for equality of variances. In Contributions to Probability and Statistics: Essays in Honor of Harold Hotelling; Olkin, I., Hotelling, H., Eds.; Stanford University Press: Palo Alto, CA, USA, 1960; pp. 278-292.

43. Wilcox, R.R. Introduction to Robust Estimation and Hypothesis Testing; Academic Press: London, UK, 2012.

44. Gil-Guirado, S.; Espín-Sánchez, J.; Del Rosario Prieto, M. Can we learn from the past? Four hundred years of changes in adaptation to floods and droughts. Measuring the vulnerability in two Hispanic cities. Clim. Chang. 2016, 139, 183-200. [CrossRef]

45. O'Kelly, M.E. A geographer's analysis of hub-and-spoke networks. J. Transp. Geogr. 1998, 6, 171-186. [CrossRef]

46. Ratliff, H.; Sicilia, G.; Lubore, S. Finding the n Most Vital Links in Flow Networks. Manag. Sci. 1975, 21, 531-539. [CrossRef]

47. IPCC. Climate Change 2014: Synthesis Report. Contribution of Working Groups I, II and III to the Fifth Assessment Report of the Intergovernmental Panel on Climate Change; IPCC: Geneva, Switzerland, 2014; p. 169.

48. Lhomme, S.; Diab, Y.; Laganier, R.; Serre, D. Urban technical networks resilience assessment. In Resilience and Urban Risk Management; Serre, D., Barroca, B., Laganier, R., Eds.; CRC Press: London, UK, 2012; pp. 109-117.

49. Cova, T.; Church, R. Modelling community evacuation vulnerability using GIS. Int. J. Geogr. Inf. Sci. 1997, 11, 763-784. [CrossRef]

50. Sheffi, Y. Urban Transportation Networks: Equilibrium Analysis With Mathematical Programming Methods; Prentice-Hall: Upper Saddle River, NJ, USA, 1984.

51. Esmaelian, M.; Tavana, M.; Santos Arteaga, F.J.; Mohammadi, S. A multicriteria spatial decision support system for solving emergency service station location problems. Int. J. Geogr. Inf. Sci. 2015, 29, 1187-1213. [CrossRef]

52. Di Matteo, U.; Pezzimenti, P.M.; Astiaso Garcia, D. Methodological Proposal for Optimal Location of Emergency Operation Centers through Multi-Criteria Approach. Sustainability 2016, 8, 50. [CrossRef]

53. Hyman, R.C.; Potter, J.; Savonis, M.; Burkett, V.; Tump, J. Why Study Climate Change Impacts on Transportation? In Impacts of Climate Change and Variability on Transportation Systems and Infrastructure: Gulf Coast Study, Phase I; Savonis, M.J., Burkett, V., Potter, J., Eds.; Department of Transportation: Washington, DC, USA, 2008; pp. 1-34.

54. Neumann, J.E.; Price, J.; Chinowsky, P.; Wright, L.; Ludwig, L.; Streeter, R.; Jones, R.; Smith, J.B.; Perkins, W.; Jantarasami, L.; et al. Climate change risks to US infrastructure: Impacts on roads, bridges, coastal development, and urban drainage. Clim. Chang. 2015, 131, 97-109. [CrossRef]

(C) 2019 by the authors. Licensee MDPI, Basel, Switzerland. This article is an open access article distributed under the terms and conditions of the Creative Commons Attribution (CC BY) license (http:/ / creativecommons.org/licenses/by/4.0/). 